6-1-2009

\title{
Strategic management and organizational behavior in dental education: reflections on key issues in an environment of change.
}

\author{
David G. Dunning \\ University of Nebraska Medical Center, ddunning@unmc.edu \\ Timothy M. Durham \\ University of Nebraska Medical Center, tdurham@unmc.edu \\ Brian M. Lange \\ University of Nebraska Medical Center, blange@unmc.edu \\ Mert N. Aksu \\ University of Nebraska Medical Center
}

Tell us how you used this information in this short survey.

Follow this and additional works at: https://digitalcommons.unmc.edu/cod_articles

Part of the Dentistry Commons

\section{Recommended Citation}

Dunning, David G.; Durham, Timothy M.; Lange, Brian M.; and Aksu, Mert N., "Strategic management and organizational behavior in dental education: reflections on key issues in an environment of change." (2009). Journal Articles: College of Dentistry. 4.

https://digitalcommons.unmc.edu/cod_articles/4

This Article is brought to you for free and open access by the College of Dentistry at DigitalCommons@UNMC. It has been accepted for inclusion in Journal Articles: College of Dentistry by an authorized administrator of DigitalCommons@UNMC.For more information, please contact digitalcommons@unmc.edu. 


\title{
Strategic Management and Organizational Behavior in Dental Education: Reflections on Key Issues in an Environment of Change
}

\author{
David G. Dunning, Ph.D.; Timothy M. Durham, D.D.S., M.P.A.; Brian M. Lange, Ph.D.; \\ Mert N. Aksu, D.D.S., J.D., M.H.S.A. \\ Abstract: With issues such as shrinking revenue, access to care, faculty workloads, and graying faculty, dental schools are faced \\ with difficult challenges that fall to dental school deans to manage. Do dental school deans have the organizational skill sets and \\ ethical frameworks necessary to address the challenges now facing dental schools? The purpose of this article is to pose questions \\ and suggestions regarding some of the key issues in dental colleges today and to stimulate discussion in the dental community \\ about needed changes in dental education.
}

Dr. Dunning is Professor, Department of Oral Biology, College of Dentistry, University of Nebraska Medical Center; Dr. Durham is Professor and Chair, Department of Hospital Dentistry, College of Dentistry, University of Nebraska Medical Center; Dr. Lange is Professor, Department of Oral Biology, College of Dentistry, University of Nebraska Medical Center; and Dr. Aksu is Associate Professor and Dean, School of Dentistry, University of Detroit Mercy. Direct correspondence and requests for reprints to Dr. David Dunning, Department of Oral Biology, College of Dentistry, University of Nebraska Medical Center, 40th and Holdrege Streets, Lincoln, NE 68583-0740; 402-472-1325 phone; 402-472-2551 fax; ddunning@unmc.edu.

Key words: leadership, ethics, access, dental colleges, faculty workload, strategy, management

Submitted for publication 12/19/08; accepted 3/4/09

"I am convinced that if the rate of change within an organization is less than the rate of change outside, the end is near."

-Jack Welch, former CEO, General Electric

$\mathrm{T}$ This warning from Jack Welch echoes the present challenges in dental colleges throughout the United States. Some of the economic challenges and strategic implications for state-supported colleges were elucidated by Bailit et al. ${ }^{2}$ Reduced state funding, higher expectations to contribute to the research mission of the broader institution (especially to secure grants), a growing income gap between practicing dentists and their dental educator colleagues, and the expectation that dental schools will serve as a safety net to help fill the access to care gap for people with no dental insurance or financial resources are among the many forces impacting dental schools. The effect of these forces speaks volumes about the rate of change largely external to dental colleges - change profoundly influencing how dental schools function in their missions of teaching, research, and service. There would appear to be no end in sight for the trends articulated by Bailit et al., resulting in the use of the word "crisis" to describe the situation now faced by many dental schools.

The purpose of this essay is to pose questions and to stimulate discussion in the dental community about some of the key issues facing dental colleges, particularly those informed from the vantage point of strategic management and organizational behavior. We don't claim to have solutions for these predicaments. We will offer some observations as contributions to ongoing deliberations in the dental education community at large. We are also not concentrating on curriculum changes or the incredibly troubling current economic issues, other than to acknowledge these are foundational components of our present milieu. Considerable attention has and will continue to be devoted to curricular issues at national meetings and discussions stimulated by the American Dental Education Association's Commission on Change and Innovation. ${ }^{2,3}$ Further, some of what we write here may challenge mainstream thought and may even offend some readers. In fact, we expect most readers to take exception with something written in this exploration of ideas. In discussing some of the challenges facing dental colleges, we will focus briefly on these key issues: leadership and organizational 
structure, access to care, ethical decision making and behavior, faculty workload, and a Strategic Alignment Pyramid.

\section{Leadership and Organizational Structure}

Bailit et al. astutely observed, "It is times of great challenge that require great leaders to step forward and build the political consensus needed" in dental education (p. 108). ${ }^{2}$ But exactly what leadership styles are needed to address the challenges facing dental education?

Leadership research and models demonstrated decades ago two key dimensions of leadership: getting the job done (task orientation, sometimes known as structure) and relating to people (relationship orientation). ${ }^{4,5}$ Various leadership styles emerge from the degrees to which each of these dimensions is demonstrated by a leader. For many years the ideal leader was thought to be "team"-oriented, meaning in part that he or she displayed high levels of both task emphasis and relationship orientation. Contingency models of leadership have emerged in more recent years, suggesting some sense of the proper fit between leaders and their environments. For example, when leading in "difficult" situations (multitudes of competing internal and external interests, relatively difficult relationships, and so forth), a more direct form of nonparticipatory leadership might be more effective than a "team leader." Is such a direct style of leadership needed at times in dental education today? Put more precisely, should such a style at least be included in the leadership adaptability or skill set of a dean?

Recently, Cohen and Tedesco ${ }^{6}$ thoroughly discussed issues of leadership in dental education, including distinguishing between technical and adaptive challenges. Technical challenges involve problems that can be solved with experts and authorities, whereas adaptive challenges involve identifying and closing the gap between current reality and aspirations. Cohen and Tedesco further differentiated the concept of authority (services in exchange for power) from leadership (activity and behavior addressing adaptive challenges). Adaptive leadership thus in a sense reaches beyond authority per se, challenging the status quo through the judicious exercise of authority and creating a "dangerous" situation in which the "values, beliefs, and ingrained ways of operating" are questioned.
We applaud the traditional ethos of academia in which internal and external consensus are built over time through collaboration. This is the time-honored way of the proper exercise of authority-yet it may fall short of the concept of adaptive leadership. Consensus-building takes an incredible amount of time and may lack certain efficiencies given the economic and political constraints faced by dental colleges.

And what of the organizational structures of dental schools? It seems - and this will not be popular with our faculty colleagues - that the traditional departmental, section type of organizational structure (and related authority processes/policies typifying many dental schools) may exhibit inadequate flexibility, which delimits a college's ability to address the internal and external changes needed in today's environment. Similarly, the typically slow to move committee structures may lack the necessary versatility to recognize and manage change in a sufficiently expeditious manner.

So perhaps it is time to view our deans and other administrators more as change agents who orchestrate change judiciously. Two of the four adaptive leadership competencies delineated by Cohen and Tedesco are facilitating interventions and energizing others. This type of leadership is exactly what we are suggesting is needed today. Can leaders, however, exercise this kind of adaptability amidst the realities of hierarchy, power, and authority typical in dental schools (and other university settings)? The answer: certainly not without great difficulty, even with adaptive leadership competencies. Perhaps it is time to consider organizational structures with streamlined processes, with less red tape, and yet simultaneously with high levels of accountability and engaged stakeholder commitment. Admittedly, reorganizing old structures will likely mean that someone or some group probably loses something (power, authority, titles). Still, such loss for the one or the few may mean survival for the greater good of the academic dental institution.

Further complicating the exercise of adaptive leadership are the ongoing constraints faced by leaders of dental education today, including serving at the discretion of upper echelon administrators, motivating faculty and staff who are at times unengaged and recalcitrant, demonstrating skill sets across various stakeholders from alumni to politicians, advocating for licensure reform, embracing a growing role in public health, and undergirding motivation and action with moral integrity. We hope that our leaders in dental education can competently and ethically 
address these ongoing constraints as they move their institutions in closing the gap between current aspirations and reality.

\section{Access to Care}

The hue and cry of access to care seems unlikely to wane. What we find remarkably ironic, however, is that the organizations (dental schools) that arguably have the fewest resources with which to provide access for the underserved are the very entities seemingly bearing the mantle to advocate for and provide this care. Dental colleges appear to be providing care for a disproportionate percentage of patients receiving Medicaid or benefits from related government programs.

Private practitioners certainly do provide care for patients in need, seeing Medicaid patients, providing services for reduced or no fee, and participating in efforts such as Mission of Mercy (free clinics held in several states) and similar activities. Still, dental colleges seem to be willingly bearing a large and disproportionate share of the burden in terms of access to care, particularly during a time of incredibly scarce resources.

Amidst providing care for the underserved, however, a strategic opportunity has arisen, an opportunity worthy of acknowledgment. Dental colleges have developed some creative avenues for providing access to care while also enhancing (or at least maintaining) revenue. Expanded, extensive, and/or creative extramural rotations have been developed in recent years under the conceptual umbrella of service-learning. These often involve clinics providing direct or indirect payments to dental schools or clinics managed in some way by dental schools. Furthermore, some of these clinics may enjoy enhanced or augmented reimbursement schedules not necessarily available to private practitioners. In some states, for example, Health Professional Shortage Areas have federally qualified dental clinics that could be managed by a dental college with staff or faculty dentists. In some of these clinics, state-funded enhanced Medicaid reimbursement levels can resemble more closely those of a preferred-provider organization (PPO). (The University of Nebraska Medical Center College of Dentistry is one such example. Several clinics in predominantly rural areas have been and will be established to address access to care issues with enhanced reimbursement schemes and student extramural rotations.)
These creative models provide access to care for the needy, offer students some clinical experiences often not available in college patient pools, and also generate (at least for a time) self-sustaining revenue. These models also shift some if not all of the cost of providing clinical education from the dental college to the community-based clinic. However, these creative models also may present potential political strategic risk or conflict: private practitioners may organize and protest higher than normal reimbursement schemes. Potentially, such protests could even jeopardize the very existence of such models. In addition, there is the quality of education concerns over calibration of faculty at these sites with faculty in the traditional dental school setting. Nevertheless, these kinds of creative models may also exemplify the type of adaptive leadership and organizational structures likely needed in dental education today. In addition, more than ever before, it is imperative that dental college leaders articulate to local and state legislators, foundations, and others the excellent and innovative work being done to help close the gap in access to oral health care.

\section{Ethical Decision Making and Behavior}

As Lord Acton famously said, "Power tends to corrupt; absolute power corrupts absolutely."”

Presumably, deans and other dental school leaders are selected based on personal integrity and ethics, among other criteria. Still, is it possible for those who gain formal positions of power to do so through ethical means and, having done so, to retain a solid moral/ethical foundation? The answer to the former is certainly yes, it is possible; the answer to the latter is that it may be possible with some difficulty. C.S. Lewis asserted that pride is "the essential vice, the utmost evil" and that pride leads to every other vice. ${ }^{8}$ Why raise issues of ethics, morality, and pride in a discussion of dental education? Because in times like these, with the economic constraints and internal and external pressures experienced by dental schools, the tendency to "lord it over" others in order to achieve public and hidden agendas could not be more tempting for people in authority-namely, deans and other administrators above and below them in the mystery of hierarchy.

Figure 1 depicts what we have in mind. Authority and power need to be expressed in the 


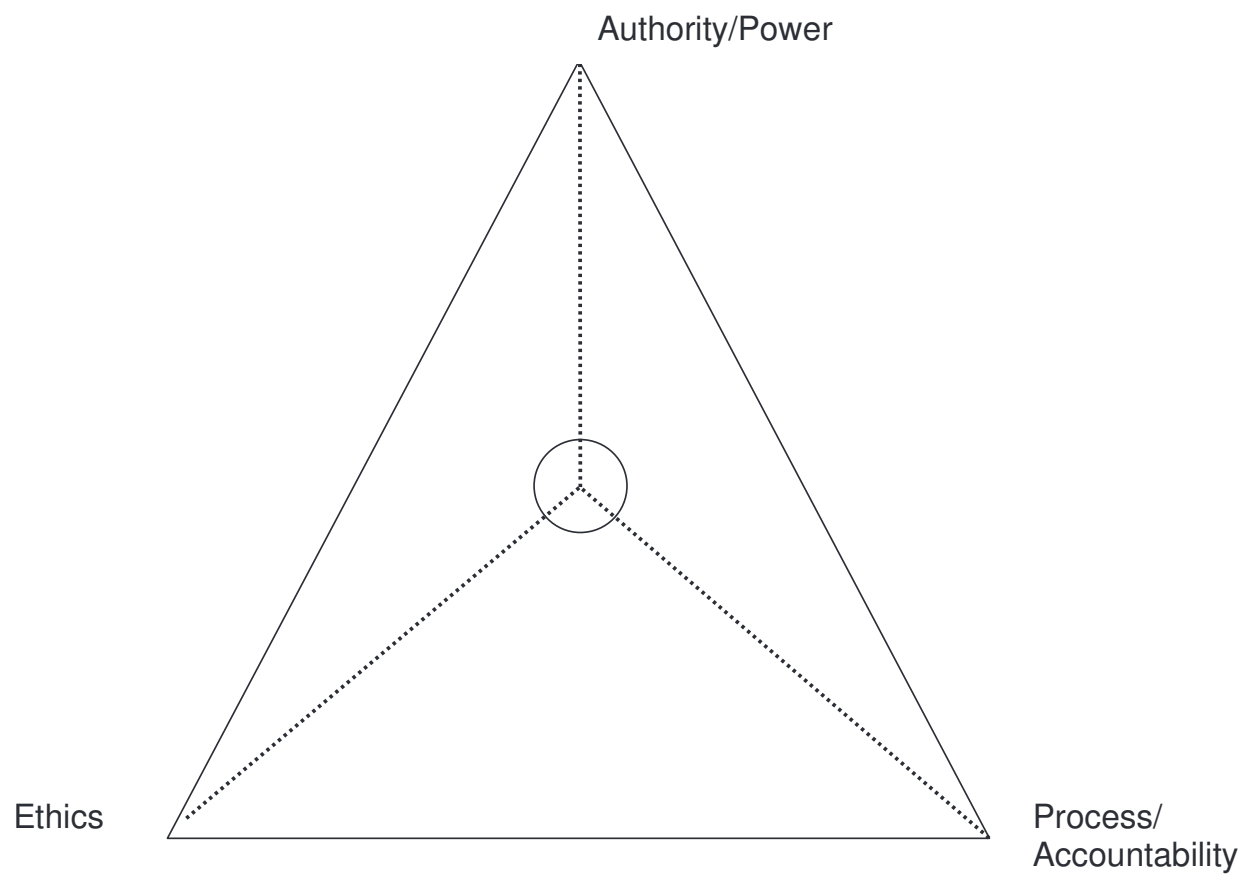

Figure 1. Ethical decision making and behavior in context

context of ethics and process/accountability. These three dimensions should meet at a centered nexus in which all three are appropriately expressed. Are stakeholders - be they faculty, staff, alumni, or practitioners - informed and involved in at least minimal and preferably meaningful levels in decisions that may change their lives? Have those in authority built relationships of trust sufficient to extend some grace in times of imminent danger, allowing a person in authority to make decisions when preferred consensus building may be difficult or perhaps impossible? Those in authority must counter the tendency for power to corrupt and, instead, be guided by uncompromising ethical principles expressed in part by relationships of trust. If ethics become compromised in leaders, so do credibility and, ultimately, effectiveness. If not already doing so, we strongly suggest that search committees fully incorporate issues of ethical decision making and behavior as part of their vetting processes, clearly delineating key ethical concerns in job descriptions and job expectations.

\section{Faculty Workload}

Dental colleges have faculty members who, in general, are not only paid significantly less than their colleagues in private practice, but who also work longer hours for this reduced pay. Dentistry is incredibly demanding work, and private practitioners reportedly work around thirty-two to thirty-six hours per week, perhaps as much as forty hours or more. ${ }^{9-11}$ Seemingly very few full-time dental faculty members work only thirty-two to thirty-six hours per week. Froeschle reported pilot data indicating that dental faculty members reported working an average of fifty hours a week in the work setting and another two to eight hours at home..$^{12}$ Trotman et al. commented on workload and quality of work-life for 
dental faculty, including these key points: 1) "work and family responsibilities clashed" (in stunning contrast to dental applicants' indicating lifestyle as a reason for wanting to become a dentist); and 2) an expectation "that academia would allow them to have more personal time than in dental practice and they would be able to maintain a predictable and standard forty-hour work week ... many junior dental faculty who were interviewed reported that they actually had little control over their work schedule and overall academic life."13

We raise this issue of faculty workload, especially hours of work per week, because this point has been relatively ignored in current discussions. A fair and rigorous formula for grasping the salary gap disparity really should factor in 1) some sense of hourly compensation or hours worked per week and 2) a more sophisticated understanding of the role that benefits play in the compensation package. The salary disparity in 2000 between dental educators and their generalist and specialist colleagues was, respectively, $\$ 86,000$ and $\$ 170,000 .^{2}$ This disparity is expected to grow to a truly staggering $\$ 278,000$ and $\$ 454,000$ (let the reader reflect!). ${ }^{2}$ Imagine dental faculty members working at least 25 percent more time per week ( 40 x $1.25=50$ hours), while also earning less. Multiply the current disparities in income by another 25 percent based on dental faculty increased workload, and you will then have a more complete picture of the magnitude of this problem. Based on this 25 percent increased workload, think in terms of year 2000 salary disparities in the $\$ 108,000$ and $\$ 213,000$ range $(\$ 86,000$ and $\$ 170,000 \times 1.25)$ and projected salary disparities in 2015 between $\$ 348,000$ and $\$ 568,000$ $(\$ 278,000$ and $\$ 454,000 \times 1.25)$.

How may job benefits factor into the understanding of overall compensation disparity? Admittedly, dental faculty may enjoy nontangible benefits (opportunities to teach and mentor) and other compensation through benefit packages, consulting, and/or private practice to help mitigate the disparity. However, the overall compensation chasm may be even worse. Why? Because income levels of private practitioners are commonly reported as taxable income. Private practitioners who are also business owners or co-owners may and often do provide much richer benefits for themselves than those provided for faculty at dental colleges in areas such as disability insurance, life insurance, continuing education, longterm care insurance, retirement contributions, automobile allowances, and so on. In a private practice, most of these benefits would be included as part of overhead business expenses and would thus not likely be reported as part of a practitioner's salary. It should be noted that the current economic crisis/recession may potentially make academia a more attractive place to be, though budget cuts in academia have occurred and may continue.

Creative models, particularly for specialist dental educators, will likely have to be developed and embraced by dental schools: full pay and/or benefits for .50 FTE appointments; more opportunity for internal or external faculty practice; more flexibility in work hours; more trust and respect in the workplace; and replacement of the triple-threat faculty member (teaching, research, and service) for promotion and tenure and creation of clinical track/teaching positions eligible for promotion and tenure. ${ }^{14}$

\section{Strategic Alignment Pyramid}

Figure 2 depicts a strategic alignment model that arose from data obtained through an American Dental Education Association Council of Sections Project Pool-funded study, two associated faculty development workshops, and related discussions regarding performance appraisals in dental schools..$^{15,16}$ The model captures the hierarchy typically found in dental schools. The dean is sandwiched between the institutional levels within his or her own school and the reporting levels above (in the larger university system) and the political intrigue beyond the confines of academia. Several of the key concerns beyond academia are federal and state legislators, dental associations, and alumni.

The culture of the broader university certainly needs to be emphasized as its characteristics will directly and indirectly influence the immediate dental school environment and how it responds to internal and external pressures that come to bear upon it. Perhaps there has never been a time in which alignment with the broader university mission has been more important. Is the larger university research-intensive? Does the broader university emphasize community service and outreach more than research, and is the college aligned with that focus? Is the dental college in a direct reporting relationship with the university president/chancellor and/or is the college housed in an academic health sciences center, which itself is one of several campuses in the university system? Does the dental school dean promote his or her per- 


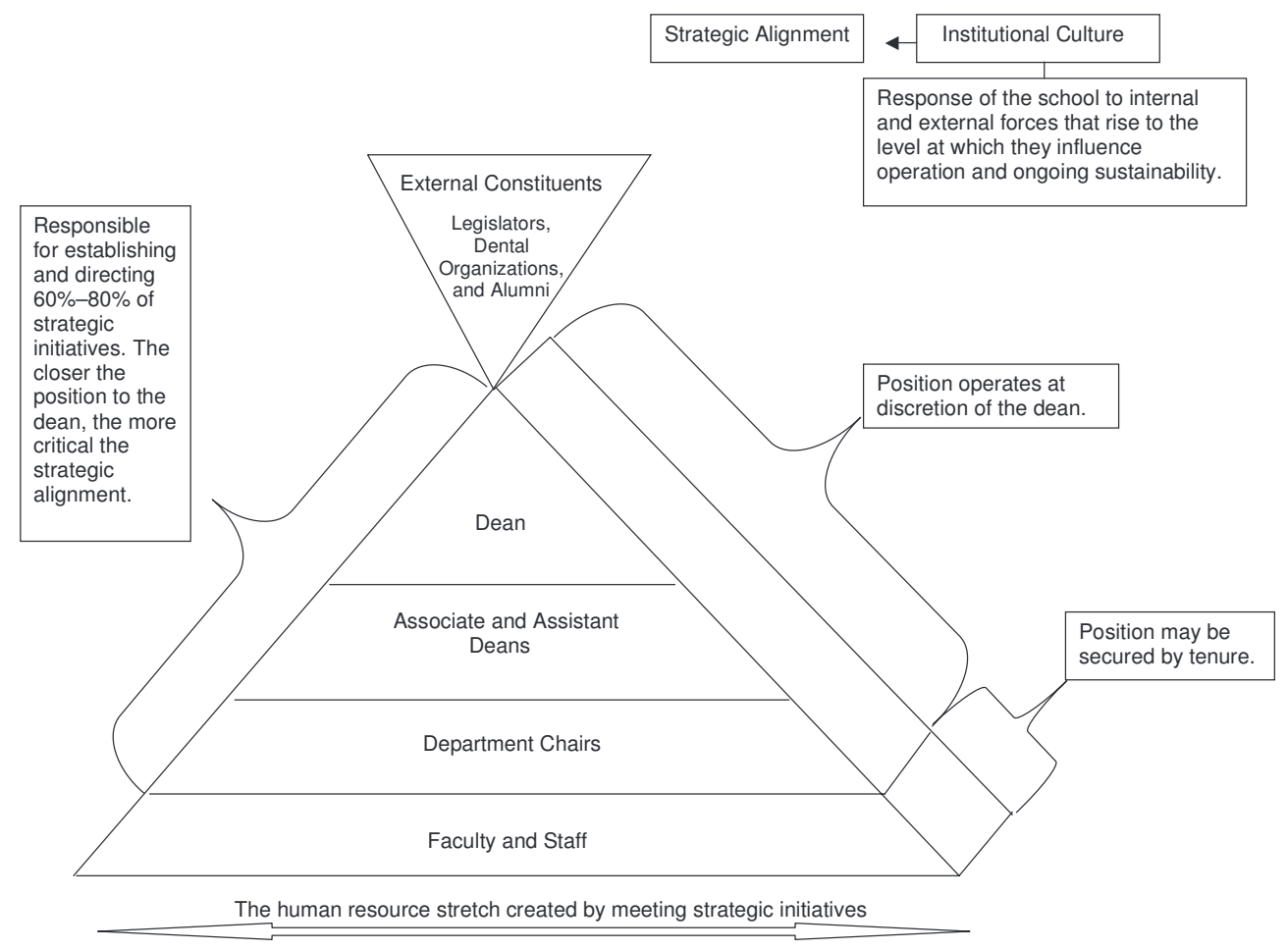

Figure 2. Strategic alignment pyramid typically found in dental schools

sonal agenda over the dental school agenda? Does collective bargaining exist? Are additional budget cuts anticipated?

Whatever the reporting relationship or structure, the dean sits at the nexus of these internal and external focuses that collectively influence operation and ongoing sustainability of the institution. The dean likely serves at the discretion of his or her supervisor. In turn, the assistant/associate deans and department chairs, in all likelihood, serve at the discretion of the dean. This discretion is critical during the challenging times currently facing dental colleges. Curiously, as discussed elsewhere, many assistant/associate deans are in non-tenure-track positions. ${ }^{17}$ These individuals may have appointments with little resemblance to traditional faculty roles and may have responsibilities aimed at helping deans achieve specific strategic initiatives (for examples, fundraising, increasing diversity of students and faculty, or managing a faculty practice).

Deans, assistant/associate deans, and department chairs probably establish and direct the vast majority of strategic initiatives in teaching, research, and service. Faculty positions toward the bottom of the pyramid may be secured by tenure, although, arguably, its importance may be inversely related to placement in the hierarchy: that is, tenure may be more important to faculty members and department chairs than to their colleagues in administration at higher levels. 
As deans and other administrators establish and direct strategic initiatives, human resources, especially at faculty and staff levels, are stretched to meet priorities. An example of this stretch is the allocation of faculty time to teaching vs. research. In order to compete for grants successfully, research-intensive faculty positions (with no or very limited teaching responsibility) have seemingly become necessary despite the fact that these research dollars come at a high cost. This, in turn, shifts more teaching responsibility to faculty members who are not research-intensive, so faculty members may become specialized to some extent. Hence, the rise of faculty clinical tracks, which may or may not involve tenure.

\section{Conclusion}

In a changing academic environment that is increasingly pressured by fiscal cycles and conflicting strategic initiatives, more traditional models of governance and leadership may be waning. The ability to secure strategic alignment given these internal and external pressures is a daunting task for leaders, as well as being confusing and frustrating for faculty members as they respond, stretch, and extend to carry out their multiple roles within the dental school. We currently have administrative and organizational models that seem at times out of step with what is needed in dental education. The issues revolve around adapting, restructuring, and reinventing. Do we see our deans as ethical, relationship-building, and benevolent leaders? Can we count on faculty members to embrace the curriculum change that will be required? Will alumni along with state dental associations become more involved in securing and providing needed funding for dental schools? What incentive packages can be negotiated in order to attract quality faculty? No one solution or formula exists. Rather we all face common concerns of quality leadership, faculty retention, reduced funding, unfunded mandates, or expectations.

Dental educators more than ever need to address the issues facing dental education. The question is: will ongoing efforts to address these issues result in successful changes in a time of adaptability?

\section{REFERENCES}

1. At: www.mbadepot.com/content/12596/. Accessed: May 7, 2009.

2. Bailit HL, Beazoglou TJ, Formicola AJ, Tedesco LA, Brown LJ, Weaver RG. U.S. state-supported dental schools: financial projections and implications. J Dent Educ 2008;72(2 Suppl):98-109.

3. Hendricson WD. The ADEA CCI series of articles: perspectives and reflections in dental education (PRIDE). J Dent Educ 2009;73(2):160-5.

4. Bass BM, Stogdill RM. Bass \& Stogdill's handbook of leadership: theory, research, and managerial applications. 3rd ed. New York: Free Press, 1990.

5. Bolman LG, Deal TE. Reframing organizations: artistry, choice, and leadership. San Francisco: Jossey-Bass, 1997.

6. Cohen PA, Tedesco LA. Willing, ready, and able? How we must exercise leadership for needed change in dental education. J Dent Educ 2009;73(1):3-11.

7. At: www.bartleby.com/59/13/powertendsto.html. Accessed: November 13, 2008

8. Lewis CS. The great sin. In: Mere Christianity. New York: MacMillan, 1952, chapter 18.

9. Steward J, Steward L. What do dentists really want? Fort Collins, CO: ManageDent Pros Publishing, 2007.

10. At: www.datpat.com/resource_center.php?page-forme. Accessed: November 14, 2008.

11. Delta College, Counseling/Advising \& Career Services. Dentist. At: www.delta.edu/PDFFiles/CareerEmployment\%20Services/dentist07.pdf. Accessed: November 14, 2008

12. Froeschle ML. A stress management survey of dental faculty. J Dent Educ 2004;68(7 Suppl):69 (abstract P22).

13. Trotman CA, Haden NK, Hendricson W. Does the dental school work environment promote successful academic careers? J Dent Educ 2007;71(6):713-25.

14. McNally M, Dunning DG, Lange BM, Gound T. Endodontic residents' attitudes toward becoming dental educators. J Endod 2002;28(8):592-4.

15. Dunning DG, Durham TM, Aksu MN, Lange BM. The state of the art in evaluating the performance of department chairs and division heads. J Dent Educ 2007;71(4):46779 .

16. Dunning DG, Durham TM, Aksu MN, Lange BM. The state of the art in evaluating the performance of assistant and associate deans as seen by deans and assistant and associate deans. J Dent Educ 2008;72(4):458-71. 